\title{
Adam D. Frank, Taijiquan and the Search for the Little Old Chinese Man: Understanding Identity through Martial Arts
}

New York, Palgrave-McMillian, 2006, 320 p.

\section{Georges Favraud}

\section{OpenEdition}

Journals

\section{Electronic version}

URL: http://journals.openedition.org/chinaperspectives/4754

DOI: 10.4000/chinaperspectives.4754

ISSN: 1996-4617

\section{Publisher}

Centre d'étude français sur la Chine contemporaine

\section{Printed version}

Date of publication: 1 December 2008

Number of pages: 104-108

ISSN: 2070-3449

\section{Electronic reference}

Georges Favraud, «Adam D. Frank, Taijiquan and the Search for the Little Old Chinese Man: Understanding Identity through Martial Arts », China Perspectives [Online], 2008/4 | 2008, Online since 01 December 2008, connection on 21 September 2020. URL : http://journals.openedition.org/ chinaperspectives/4754; DOI : https://doi.org/10.4000/chinaperspectives.4754

This text was automatically generated on 21 September 2020.

(c) All rights reserved 


\title{
Adam D. Frank, Taijiquan and the Search for the Little Old Chinese Man: Understanding Identity through Martial Arts
}

New York, Palgrave-McMillian, 2006, 320 p.

\author{
Georges Favraud
}

1 This book is Adam D. Frank's anthropology doctoral thesis under Deborah Kapchan's direction, defended in 2003 at the University of Texas at Austin. The study is based on the author's practice of "supreme ultimate boxing," taijiquan, under the Jianquan Taijiquan Association (JTA), which was founded in Shanghai in 1935 by the martial arts master $\mathrm{Wu}$ Jianquan. Frank writes that from the perspective of discourse, this kind of transnational physical practice helps to highlight conceptions of identity (especially Chineseness) and to confirm differences (of ethnicity, social milieu, or nation). From the point of view of lived experience, however, he finds it a means of negating them. Thus the author sought to understand "identity as it is sensually experienced and culturally constructed through martial arts practice in the People's Republic of China (PRC) and the United States" (p. 4). The work is invigorated by dramatic passages and dialogues that introduce the author's ethnographic material.

The first chapter sets out the different dimensions of the work, proceeding in a complex manner along three paths: narratives concerning taijiquan, then those related to Daoism (which have recently come to be associated with taijiquan), and finally the author's preconceptions that were dismantled during his field study. In the next two chapters, Frank focuses on the dimension of identity, which he qualifies as "sensually experienced." He describes the practice and his relations with his three teachers and other members of the JTA. Taijiquan is essentially practiced by amateurs and retired people in Shanghai's parks through networks organised in the form of "associations" (whose legal status the author does not clarify). Although he says individual techniques are the foundation of techniques conducted with a partner, the author stresses the 
importance of "push hands" (tuishou), which is practised in tandem in all styles of taijiquan. When practised non-com petitively, this technique helps develop the capacity to "listen to the energy" of the partner (tingjin). Some practitioners also believe that "push hands provides an opportunity for the student to feel the teacher's qi, develop a sense of inner calm, and, ultimately, acquire the ability to read the intention of an opponent even without touching" (p. 24), as well as an ability to "instinctively size up the quality of a situation" (p. 106). One might point out that this "instinct" is not an "innate" attribute of the human species, but is intentionally embodied through the practice of techniques, and thus corresponds to the Daoist concept of spontaneity/naturality (ziran).

After dealing with individuals and their practices, in chapters 3 and 4 Frank extends his horizon to the parks and the city of Shanghai. He studies taijiquan as a "public art" observed in streets and green spaces. Then "identity moves through city and individual" (p. 145), and the practitioner's body becomes "both a recording medium of the art passed on to him or her and an actor upon the world that produces the art" ( $p$. 100). In this chapter we witness how practitioners adapt to the redevelopment of the People's Park and their participation in Taijiquan Day, sponsored by Shanghai's Xuhui district government to promote "orthodox" practices in a venue previously used by Falungong practitioners. In other words, JTA's taijiquan - along with that of many other groups collected under the taijiquan label - has the support of Chinese leaders, who want them to take over from the qigong movements that have been deemed "heterodox" since the crackdown on Falungong in 1999.

In Chapter 5, Frank approaches taijiquan as a master symbol of modernity and of the state's power of intervention in constructing identities. Analysed here as a "kinaesthetic vernacular language of state," a standardised taijiquan helps to create "imagined communities" as opposed to traditional and local forms (p. 160-161). In other words, through a patrimonialisation policy, the Chinese government - under pressure from globalisation - usurps a traditional practice to turn it into a competitive sport and leisure pastime of the masses, subjugating the practitioners' bodies and transforming their communities. The republican government had early on chosen martial arts as one of the master symbols of its campaign aimed at "strengthening the national body," and martial arts masters were urged to open their teachings to the public. The aim was to transform resentment against foreigners into a force capable of restoring China's international power. The objectives of winning medals and introducing martial arts in the Olympic Games were expressed as far back as at the start of the twentieth century. Shanghai's industrialisation and the emergence of a leisure class prompted a number of teachers to move to the city with their families. In the mid- 1920s, the first competitions were held in the form of Western sports, especially as part of programmes supported by the YMCA (Young Men's Christian Association). In the 1950s, Mao Zedong's cultural policy, first stated in Yan'an in 1942, took effect: taijiquan and other regional martial arts were categorised as "folks sports" (minzu chuantong tiyu) and enjoyed a golden age until the launch of the Cultural Revolution. Today, as part of a continuing process, an entire literature "trades on the language of modern science to validate and reify the 'traditional' (taijiquan) as an essential feature of Chinese identity" (p. 183).

5 The author also examines martial arts storytelling (Chapter 6) as a means of approaching the construction of identity. The oral tradition of martial arts is ancient, 
and is especially prominent in Beijing Opera. Towards the late nineteenth century, rhyming poems were published and distributed to convey technical instructions and martial values and myths. Today, taijiquan fiction circulates in China and overseas through novels, films, animated cartoons, and video games. The author relates his experience taking part in the filming of a Sino-US television gongfu serial called "Flatland." Unlike the practice of taijiquan in a park, reading or seeing such works is an act of imagination detached from direct experience of martial arts. Thus it is "not direct experience of the world it depicts, but it may inspire a martial arts practitioner to reconstruct that world" (p. 196). From the Cultural Revolution to the opening up policy of the 1980s, many fictional works promoted martial arts from "remnants of feudalism" to "among the highest achievements of Chinese culture" (p. 202). Since then, such works continue to nurture some representations of traditional China, especially among teenagers.

In Chapter 7, the author shows that "the history of taijiquan's dissemination into the United States is both embedded in the history of Chinese immigration and intimately related to post-World War II geopolitics, the blossoming of Hong Kong and Taiwan cinema and relatively recent changes in US policy toward China" (p. 211). As a transnational practice, martial arts channelled the movement and meeting of persons and identities, con stituting and reconstituting many forms of Chineseness. The adoption of taijiquan by the US counter-culture of the 1970s persuades Frank to form the hypothesis of an American taijiquan as a "resistance to state control of the body," situating it in this respect within the continuity of China's Daoist tradition. Observing the commercial pull of taijiquan DVDs, the author shows how this practice is integrated in new age and fitness discourse on health. The martial aspect of the art is thus overshadowed by its association with the power and beauty of nature, through its role in toning muscles and burning fat, or in relieving stress. Adam Frank's analysis of the basis of a trans-national discourse on qi (breath, vital energy) is also edifying: "The attempt to define the word actually provides one of the chief contexts for using it. In addition, even while the definition of qi remains unclear to the members of this community in which it appears it is the very act of using the word that produces social solidarity, enhances the speaker's status, and evokes a shared image of the exoticized Chinese other" (p. 220). Moreover, rather than learning mere martial techniques, it seems that many Americans (and no doubt many other Westerners) are even more interested in learning the "philosophy" of martial arts; while practising, they seek thus to "actually become Chinese for a few hours" (p. 215).

7 The distinction Frank makes between what is "sensually experienced" and what is "culturally constructed" constitutes one of the work's guidelines. It is useful in showing how, especially in the globalised context, practicing with the "other" helps forge communication between persons beyond identity prejudices. But this distinction sometimes seems too neat. The choice not to integrate the concept of "person" and focus on social relations seems to be an obstacle to the analysis of articulations between representations, body, and techniques. Adam Frank devotes the core of his analysis of techniques to a movement practiced in tandem (push hands). Other techniques, such as those I have observed in a Daoist temple in a village in central China, are founded on solitary practice, slow and even immobile. Before sensually experiencing the bodyperson of the "other" (with the help of the technique of push hands, for example), listening to oneself constitutes the first necessary stage in proceeding towards determination and stabilisation (ding) of personality (xing). Although the author 
stresses that identity is "wired into our bodies through repeated experience and interpretation of this experience" (p. 11), constituting a "stock of sedimented social knowledge" (p. 62) - in other words, that this experience has become spontaneous (ziran) - he concludes that this incorporated knowledge is shared and sensually experienced during practice. Ancient Chinese cosmology - as actualised by the Daoists I have observed - considers quietude (jing) and movement (dong) to be two complementary and inseparable principles. The practices of quietude (jinggong) are focused on quieting one's own body-person (the term "body" also invokes the notion of "person," as can be noted in the double meaning of the term shen). By stopping body movement and ceaseless storytelling projected on the world, a harmonisation of self to the cosmos emerges. In other words, the practitioner proceeds through the techniques to the source of the concepts and values that give structure to the community and individuals. Then on this foundation is deployed - through "senses that take direction" - a movement (dong) synonymous with taking position in relation to the other and to the immediate environment. What makes taijiquan a technique rather than an aggregate of gesticulations are the representations and objectives, the intentions and the meanings, that the person associates with these movements, as well as the efficacy the community attributes to their execution. Such an anchoring in the body-person and in the process of incorporation would have helped the author to clarify the concept, often apparently fluid and ethereal, of "identity" that he defines as being in perpetual movement between different spaces (People's Park, teacher's flat, Shanghai city, sport tournament, the United States ...) and levels of discourse (Daoist "tradition," whimsical past, government policy, new age...).

8 As he bases his analysis on a modern association of Shanghai and then turns his attention to the United States, Frank is also led straight into the complexity of a globalised society. He does describe the historical process of taijiquan's modernisation, but does not begin with the symbols and social organisations in which the techniques have their origins (i.e. Chinese body culture before its globalisation). Daoists of the Complete Authenticity (Quanzhen) tradition - the body techniques specialists I am studying - appear to be a good example of an alternative elaboration and socialisation of the body-person, but articulated with the imperial social organisation. These Daoists take part in a tradition and a community on the basis of a "predestined affinity" (yuanfen) between master and disciple. They leave their birthplace and their family (chujia), a decision not taken lightly in an imperial society where social organisation rests on the Confucian state religion, taking the local form of farming clans making sacrifices to ancestors and the earth God. Along with mastering their ritual techniques, these Daoists acquired a personality, and then allowed adherents to short-circuit the Confucian hierarchy by communicating in their village with their tradition's divinities: ancestral masters (zushi) of their celestial hierarchy and their cosmological principles.

During the identity crisis around the start of the twentieth century that Frank deals with in Chapter 5, quietude (jing) was seen as part of the Asian sick man's storytelling and of the Chinese nation's immobility. The myths of modernity's techno-scientific, economic, and political development - associated with movement (dong) - were transforming Chinese culture and its body techniques. Since that time, the cosmological roots underpinning Chinese body culture have been confronted with the cosmology and the social organisations of a Western-impelled modernity. While showing that modernisation modified the environment of JTA's techniques, Adam Frank reproduces accounts that on the one hand describe the evolution of these 
techniques as a martial art tending towards a healthy practice, and on the other hand stress the absence of young men in the group and interpret it as a sort of "emasculation" (p. 115). Many practitioners therefore appreciate sessions embellished by demonstrations or storytelling of power. I have been confronted with similar accounts: some practitioners express their appreciation for narratives of the fights of "heroes" who went to the city to establish their schools; others the wish to study the "martial applications" of movements. Certainly in the Shanghai of the current decade, violence is more symbolic than in a republican era village. However, this question of taijiquan's martiality and of Chinese "virility" merits attention.

In one Daoist oral tradition reported to me, taijiquan was created by Daoist Zhang Sanfeng in the Ming Dynasty. After mastering Daoist meditation techniques, he had yet to attain a satisfactory state of health and quietude. He then came up with movement techniques, first to nurture life (yangsheng), and then to defend his living space in case of aggression. This version's historic truth is contradicted by historians who trace taijiquan's origin to the martial art of the Chen family in nineteenth century Henan. Without entering into historical debate, it seems to me that the theory adopted by Adam Frank does not situate these techniques in the dynamic of chinese body culture wherein martial, medical, and meditation rituals have long cohabited in different communities. For instance, many ancient hagiographies of Daoist and Buddhist masters attribute them with skills in multiple domains. In my observation, there is no profound anatomical or motivational difference between these different aspects of Chinese body techniques. The differences are basically in the representations each person attributes to them. Thus, meditation, medicine, and martial arts may easily constitute three axes for analysing a Chinese ritual such as taijiquan. Throughout generations, it has been the capacity of some people to interpret and master its techniques that explains the presence of as many variants of taijiquan as there are masters. Thus, over time, techniques have changed and communities have appeared and disappeared along with the traditions that brought them together. The theory isolating taijiquan from the historical, symbolic, and sociological context of its origins therefore seems to carry the risk of helping reconstruct a history that legitimates a taijiquan label used as an identity mark of a modern and shining China. To the ethnologist, the two contradictory discourses (taijiquan's origin in combat or in meditation) could more simply express the meaning attached to the techniques by different practitioners from diverse communities. The talk of a feeling of emasculation indicates that the identity crisis that compelled China a century ago to "strengthen the national body" has yet to be resolved.

11 If a limitation in Frank's work needs to be pointed out, it is in the lack of analysis of techniques, especially in their relationship to individuals and their cultural origin. Perhaps the relative lack of structure of the work can be explained by the difficulty of formulating a synthesis between the pertinent anthropological tools and the profusion of fieldwork material. Frank carried out fieldwork over an extended period of time immersed in the community he studied, without which he would not have been able to carry out this first Western anthropological study of a Chinese body technique at the crossroads of martial arts, medicine, and meditation. Adam Frank's approach, situating the Shanghai taijiquan practice in a human and urban milieu and confronting it with the politics and history of its modernisation, is particularly praiseworthy. The analysis of the globalisation of these techniques and of the appearance of communities of 
practitioners in the United States, through the discourses of new age, fitness, politics, and economics - filters that no Westerner can fully escape - is also highly instructive.

12 Translated by N. Jayaram 